\title{
LATERAL COOLANT FLOW BETWEEN FUEL ASSEMBLIES IN MIXED CORES
}

\author{
VOJTĚCH CAHA ${ }^{a, b, *}$, JIŘí ČÍžEK ${ }^{b}$ \\ a Department of Nuclear Reactors, FNSPE, CTU in Prague, V Holešovičkách 2, Prague, Czech Republic \\ ${ }^{b}$ Chemcomex, a.s., Elišky Přemyslovny 379, Prague, Czech Republic \\ * corresponding author: vojtech.caha@fjfi.cvut.cz
}

\begin{abstract}
This paper presents the results of an analysis of lateral coolant flow between adjacent fuel assemblies with non-identical spacing grids in a mixed core consisting of TVSA-T mod.1 and TVSA-T mod.2 fuel assemblies. The calculation was carried out using modified subchannel code SUBCAL which allows to calculate 3D thermo-hydraulic characteristics of the coolant flow in the full three fuel assemblies model. This full three fuel assemblies model was created in two variants. The first variant consisted of three hydraulically identical fuel assemblies TVSA-T mod.1, whereas the second variant consisted of two fuel assemblies TVSA-T mod.1 and one fuel assembly TVSA-T mod.2 which mainly differ in types, number and axial coordinate of spacing grids and also in diameter of guide tubes. The influence of mixed core to lateral coolant flow and hence coolant temperature was obtained by comparing these two variants. The power distribution was taken from presumed mixed core fuel reload calculated by macro-code ANDREA. Finally there were also provided a comparison of results achieved by subchannel analysis approach with calculation of similar problem using CFD code ANSYS CFX by TVEL, the fuel supplier.
\end{abstract}

KEYwORDS: subchannel analysis, SUBCAL, mixed core, thermal-hydraulics.

\section{INTRODUCTION}

When a reactor core consists of more than one type of fuel assembly, the local flow redistributions due to differences in fuel assembly pressure drops may be introduced. The crossflow, as well as axial flow, results in flow-induced coolant temperature changes and thus may influence a heat generation in peripheral fuel rod rows. The mixed core can cause a Departure from Nucleate Boiling Ratio (DNBR) penalty with respect to the reference core consisting of only one fuel type. An important aspect of core performance evaluation is the ability to predict interchange transfer of mass and energy. Two mechanisms are identified: crossflow and thermal mixing. Crossflow involves net transfer of the coolant (both mass and energy) between assemblies or subchannels. Thermal mixing is energy exchange due to a radial enthalpy gradient with no associated net mass transfer. Modified subchannel thermal-hydraulic code such as SUBCAL [1] can be used to account for the effects of crossflow in fuel assemblies and reactor cores due to hydraulic mismatch or power gradient, and perform the mixed core DNBR calculations. Similar analysis (in simple geometry) can be also provided by CFD codes, e.g. ANSYS CFX [2].

The thermal-hydraulic subchannel code SUBCAL is developed in Chemcomex and used in the nuclear industry in Czech Republic for VVER core design, licensing applications and safety assessments of fuel cycles 3. SUBCAL was developed on the basis of COBRA code series. Similar to other subchannel codes currently used for PWR and VVER analyses,
SUBCAL predicts the three-dimensional velocity, pressure, and thermal energy fields and fuel rod temperatures for single- and two-phase flow in PWR, resp. VVER. SUBCAL solves the finite difference equations for mass, energy, axial and lateral momentum conservation for an interconnected array of channels, assuming incompressible and thermally expandable homogeneous coolant flow. Although the formulation is homogeneous, empirical models are incorporated into the code to account for subcooled boiling and vapor/liquid slip in two-phase flow.

The SUBCAL code was validated and standardized by SÚJB (Nuclear Regulatory Body of the Czech Republic) in 2010 for TVSA-T mod.0/1 fuel and is expected to be lincesed for TVSA-T mod.2 fuel in 2018.

\section{THREE FUEL ASSEMBLIES MODEL}

The three fuel assemblies model was created by connecting three separate TVSA-T fuel assemblies where the subchannels at the interface of these fuel assemblies were merged together and hence the new types of subchannels were created. The schematic drawing of three fuel assemblies model is shown in Figure 1 . The main characteristics of the three fuel assemblies model are listed in Table 1. The axial length and nodalization were taken from previous neutron-physical calculation of power distribution by code ANDREA [4]. A nonuniform axial nodalization into 96 nodes was used at total length of $3730 \mathrm{~mm}$, thus each node length was within range 20.7 to $44.5 \mathrm{~mm}$. 


\begin{tabular}{lc}
\hline Parameter & Number [-] \\
\hline Subchannels & 1986 \\
\hline Types of subchannels & 27 \\
\hline Boundaries & 3033 \\
\hline Types of boundaries & 27 \\
\hline Rods & 993 \\
\hline Axial nodes & 96 \\
\hline
\end{tabular}

TABLE 1. Subchannel model of three fuel assemblies.

\begin{tabular}{cc}
\hline Type & TVSA-T \\
\hline 1 & Mod.2 \\
\hline 2 & Mod.2 \\
\hline 3 & Mod.2 \\
\hline 4 & Mod.1 \\
\hline 5 & Mod.1 \\
\hline
\end{tabular}

TABLE 2. Types of spacing grids.

For the purposes of assessing the influence of the mixed core on the coolant temperature, two variants of the three fuel assemblies model were created. The first variant consisted of three hydraulically identical fuel assemblies TVSA-T mod.1 (Figure 2), while the other variants were composed of two fuel assemblies TVSA-T mod. 1 and one fuel assembly TVSA-T mod.2 (Figure 2). The fuel assemblies TVSA-T mod.1 and mod.2 differ, for the purpose of subchannel code calculation, in particular in the number and types of spacing grids and the diameter of the guide tubes. All types of spacing grids are shown in Table 2 and their coefficients of resistance can be found in [5]. The coefficients of resistance for Type 4 mixing grid in TVSA-T mod.1 fuel assemblies are assigned to each type of subchannel individually [3], while the Type 1 mixing grid in TVSA-T mod.2 fuel assembly requires the same coefficient of resistance for all types of subchannels.

Different types of spacing grids for TVSA-T mod.1 and mod.2 fuel assemblies are associated with different turbulent mixing coefficients values. For mod.2 fuel assemblies, the value of the trbulent mixing coefficient $\beta_{1}$ is given along the entire axial length, while mod.2 fuel assembly is divided into two axial parts. A value of $\beta_{2}$ is taken into account up to the first mixing grid (Type 1 - approx. $2500 \mathrm{~mm}$ ), whereas the second part has a turbulent mixing coefficient equal to $\beta_{3}>\beta_{2}$. All turbulent mixing coefficients were carefully set up on the basis of mixing experiments for stand-alone fuel assemblies [6]. At the interface between mod.1 and mod.2 fuel assemblies, the mean value is considered. The axial geometry of spacing grids for both types of fuel assemblies is shown in Figure 3

\section{AnAlyzed REgime PARAMEters}

All calculations were performed at the regime parameters corresponding to the diverted values for fuel cycles safety assessments at 4 working MCP (main circulation pump) and $100 \%$ thermal power 3 . The calculation regime parameters are shown in Table 3 Pin by pin power distribution was calculated by code ANDREA at 48 axial non-uniform nodes. Two mixed core cycles ( $\mathrm{T} 1$ and $\mathrm{T} 2$ ) were selected in which six different power profiles were chosen, see highlighted groups of fuel assemblies in Figure 4 Fuel assemblies whose name begins with the letter "A" are TVSA-T mod.1, while the names of fuel assemblies beginning with the letter "B" indicate the type TVSA-T mod.2.

\begin{tabular}{lc}
\hline Pressure $[\mathrm{MPa}]$ & 15.34 \\
\hline Inlet temperature $\left[{ }^{\circ} \mathrm{C}\right]$ & 293.8 \\
\hline Mass flow $\left[\mathrm{m}^{3} \mathrm{hod}^{-1}\right]$ & $1425(3 \times 475)$ \\
\hline Reactor thermal power $[\mathrm{MW}]$ & 3245 \\
\hline
\end{tabular}

TABLE 3. Regime parameters.

\section{Results}

Each of the six power profiles was set as an input and calculated for both three fuel assemblies model variants by subchannel code SUBCAL, i.e. three TVSA-T mod.1 fuel assemblies and also two fuel assemblies TVSA-T mod.1 and one TVSA-T mod.2 (see Figure 2), so that these variants can be compared.

The evaluation was carried out in the boundary of mod.1-mod.1 fuel assemblies (var. 1), resp. mod.1mod.2 (var. 2), see highlighted rods and subchannels in Figure 5. The evaluated boundaries, subchannels and rods are grouped in graphs with results according to colored rows.

The following Figures 6 and 7 show the axial distribution of cross-flow velocities. A positive value indicates that the flow proceeds from the first to the second subchannel listed in the legend of each figure. In all rows according to Figure 5 the same direction of positive flow velocity is maintained. For example, the positive cross-flow velocity value at "B. 1072-981" expresses flow from subchannel no. 1072 to subchannel no. 981, in the case of negative value it is opposite direction.

Figures (8) and 9) plotting the axial distribution of the coolant temperature shows coolant temperature differences around the rod between variant 1 (three TVSA-T mod.1) and variant $2(\bmod .2$ and two mod.1). For example, a positive value indicates that the coolant temperature at a given axial position is lower in variant 2 than in variant 1. 


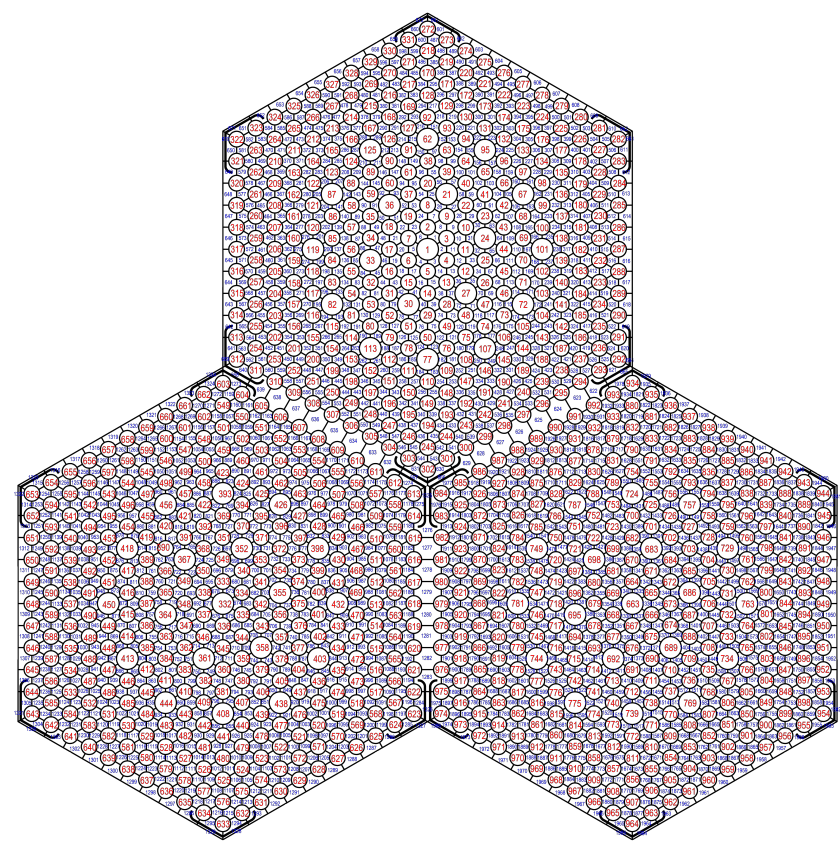

FiguRE 1. Three fuel assemblies model with rod and subchannel numbering.

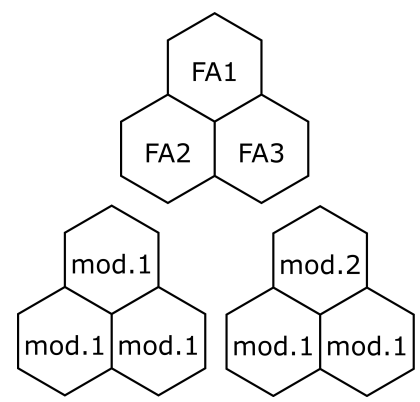

FIGURE 2. Three fuel assemblies calculation variants.

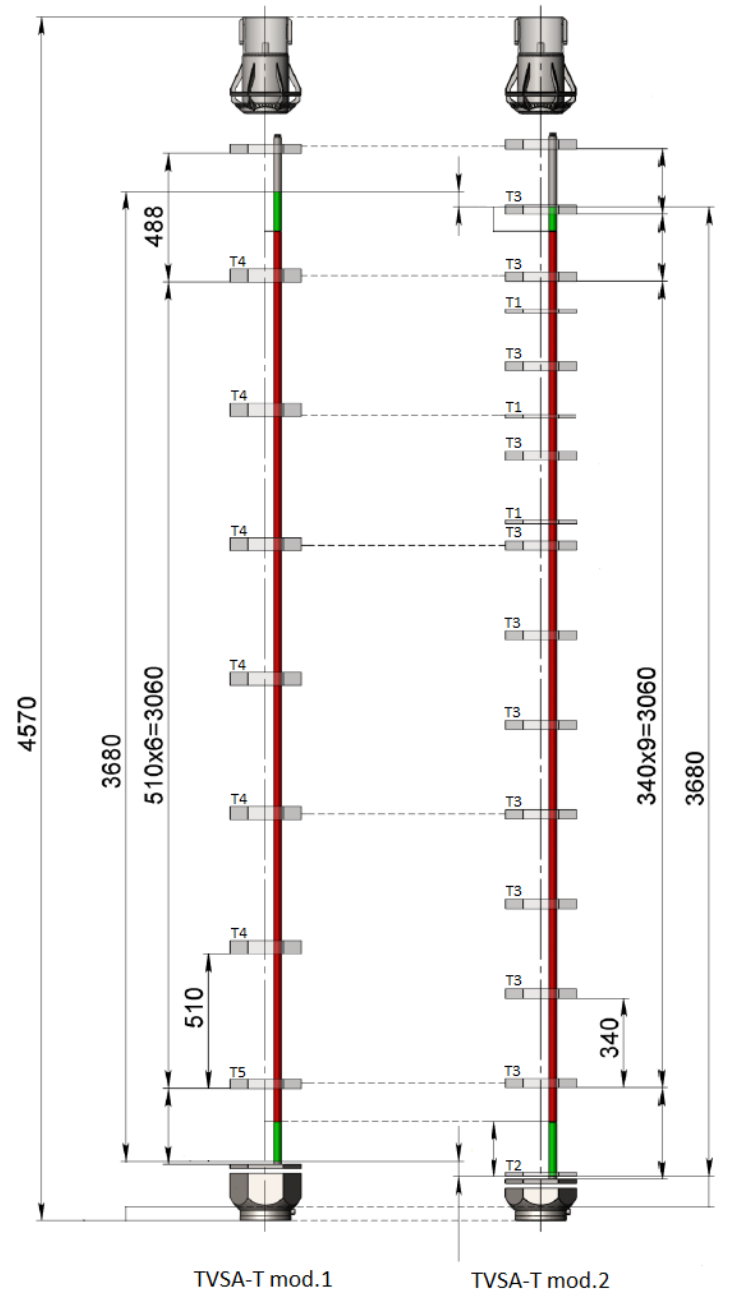

Figure 3. Axial geometry of both types TVSA-T. 2] 

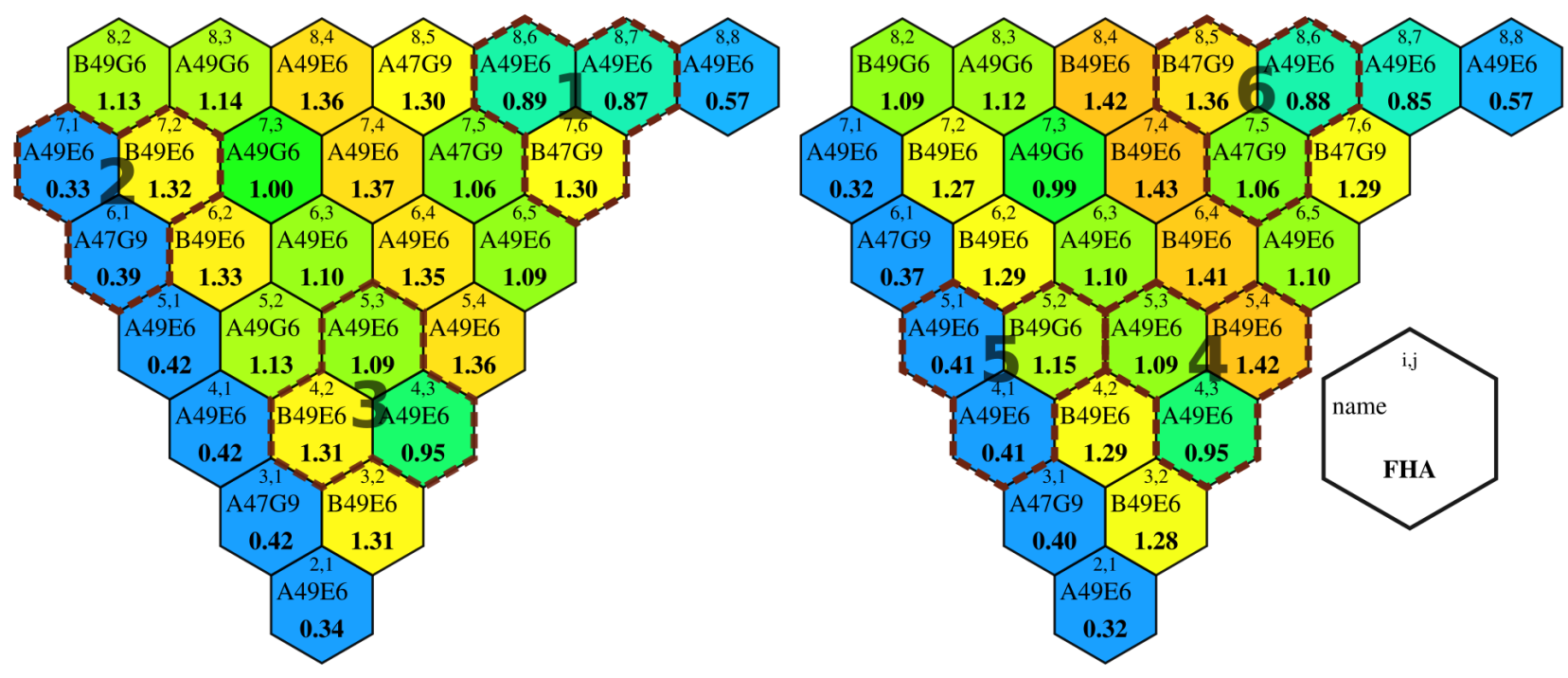

Figure 4. Calculated power profiles T1 and T2. 4]

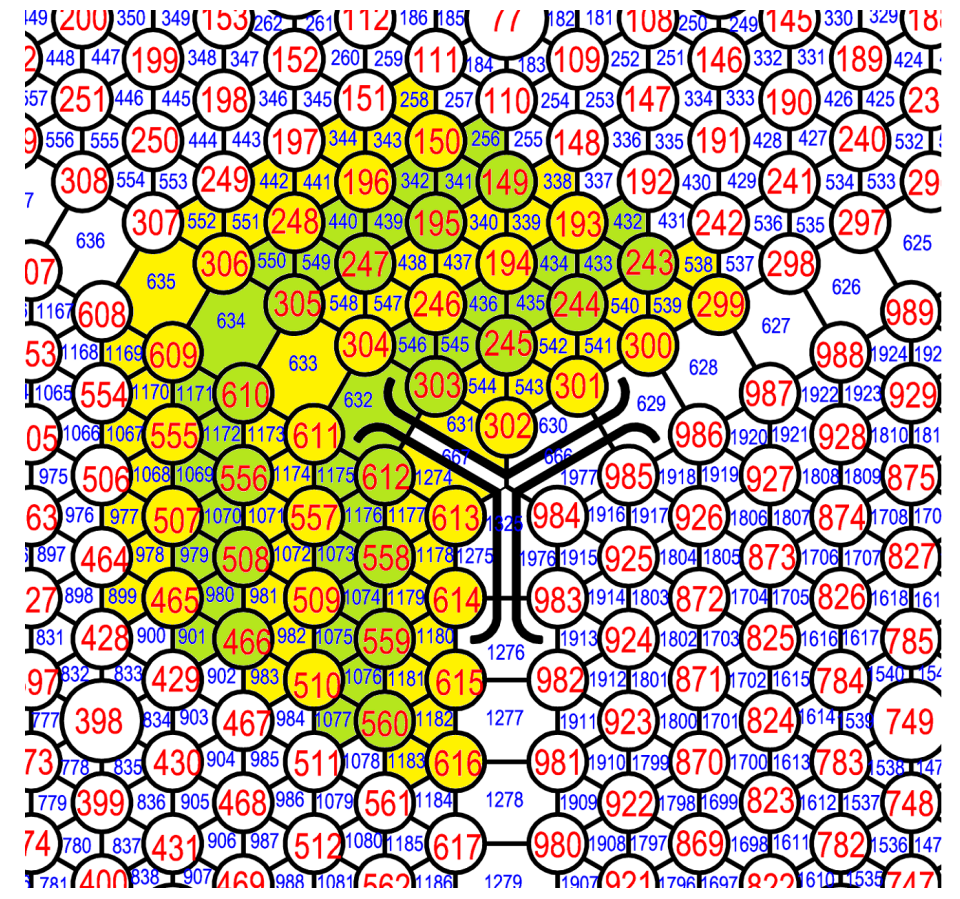

Figure 5. Areas of evaluation of lateral coolant flow and coolant temperature around rods. 


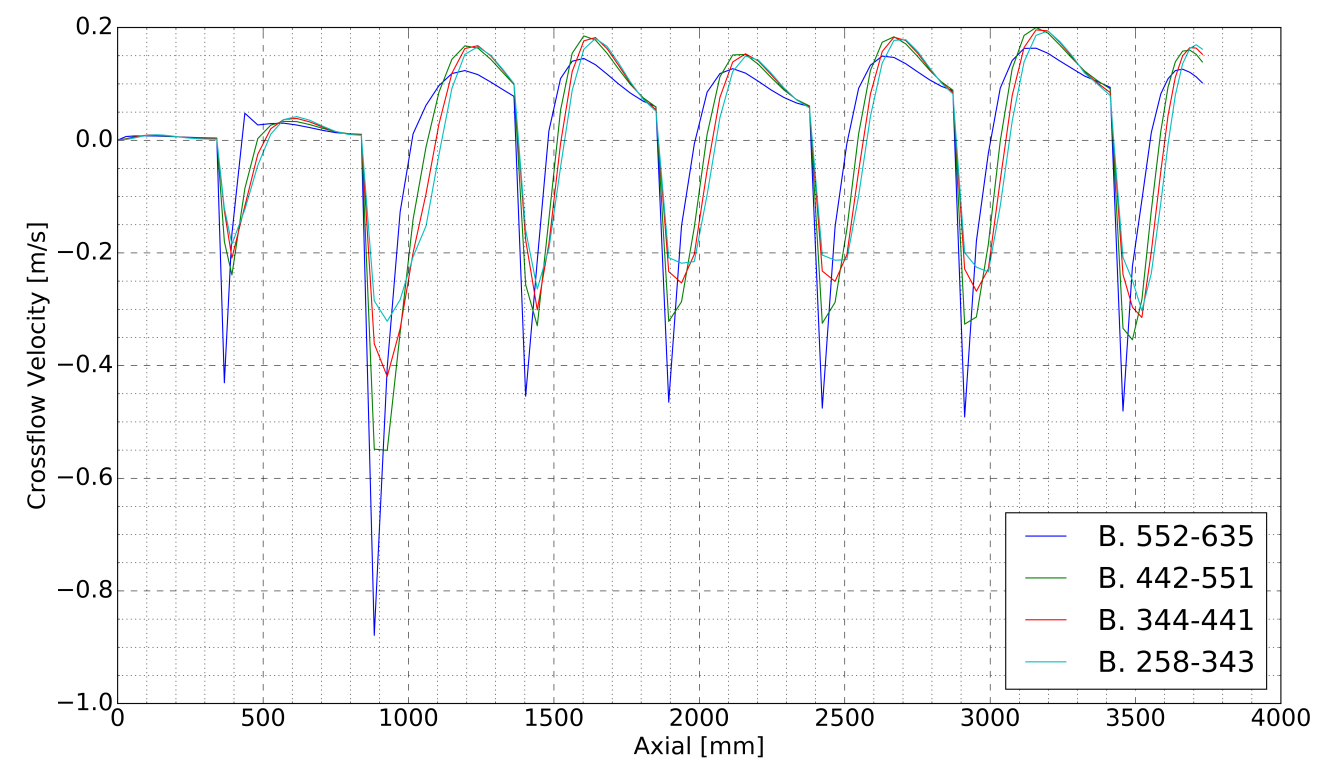

FiguRE 6. Example of crossflow velocity - variant 1.

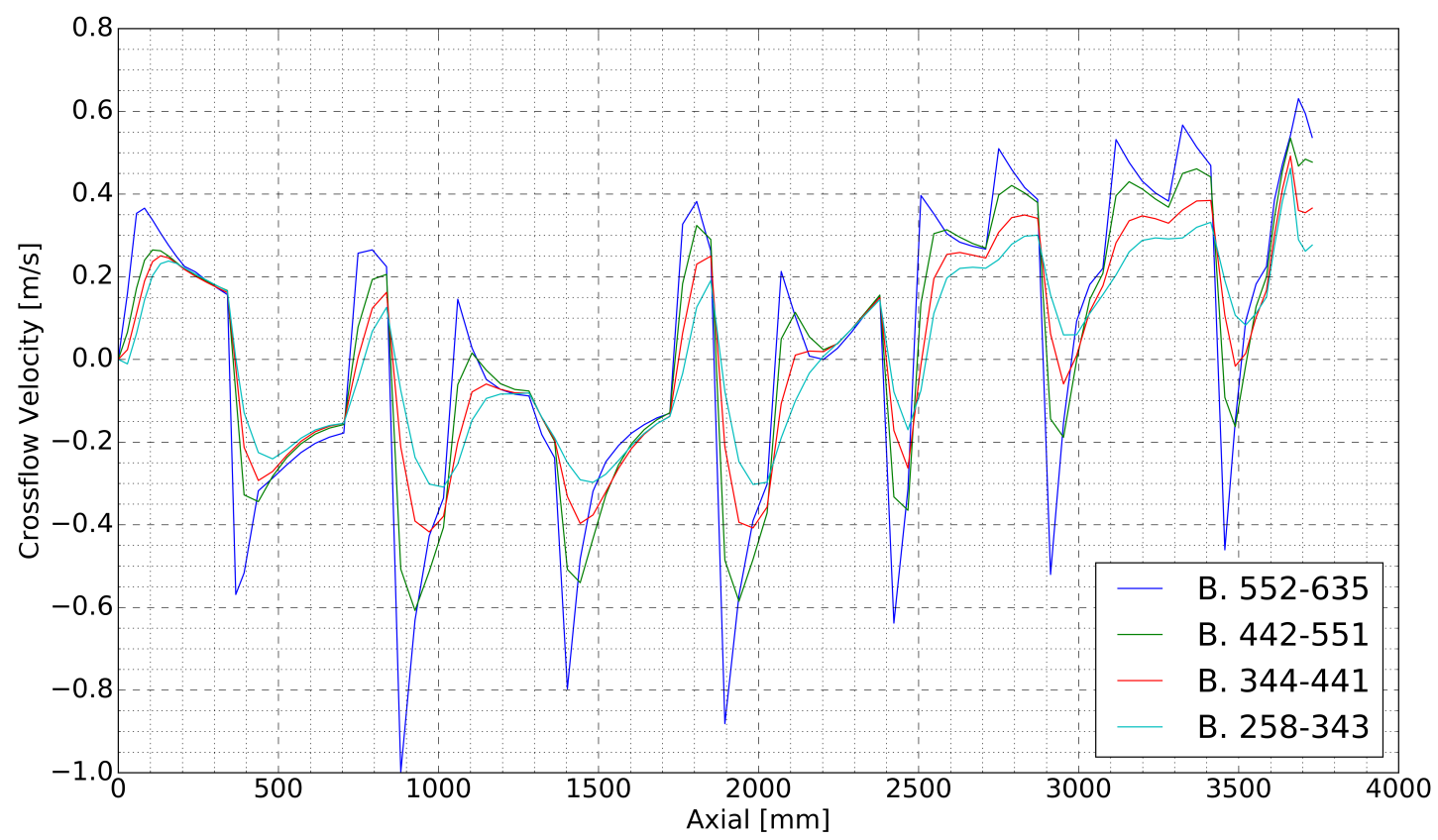

FIgURE 7. Example of crossflow velocity - variant 2. 


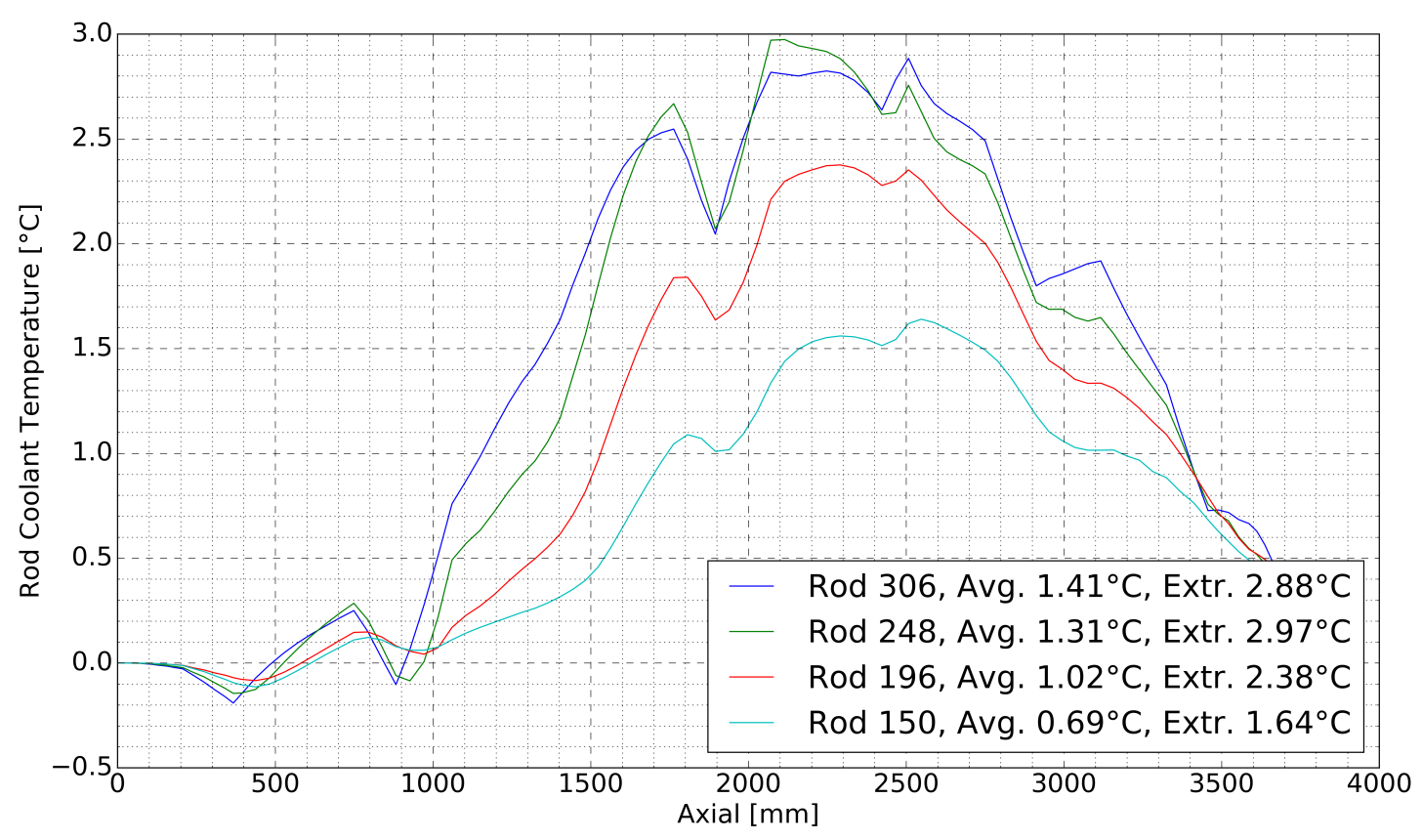

Figure 8. Example of rod coolant temperature differences - FA1.

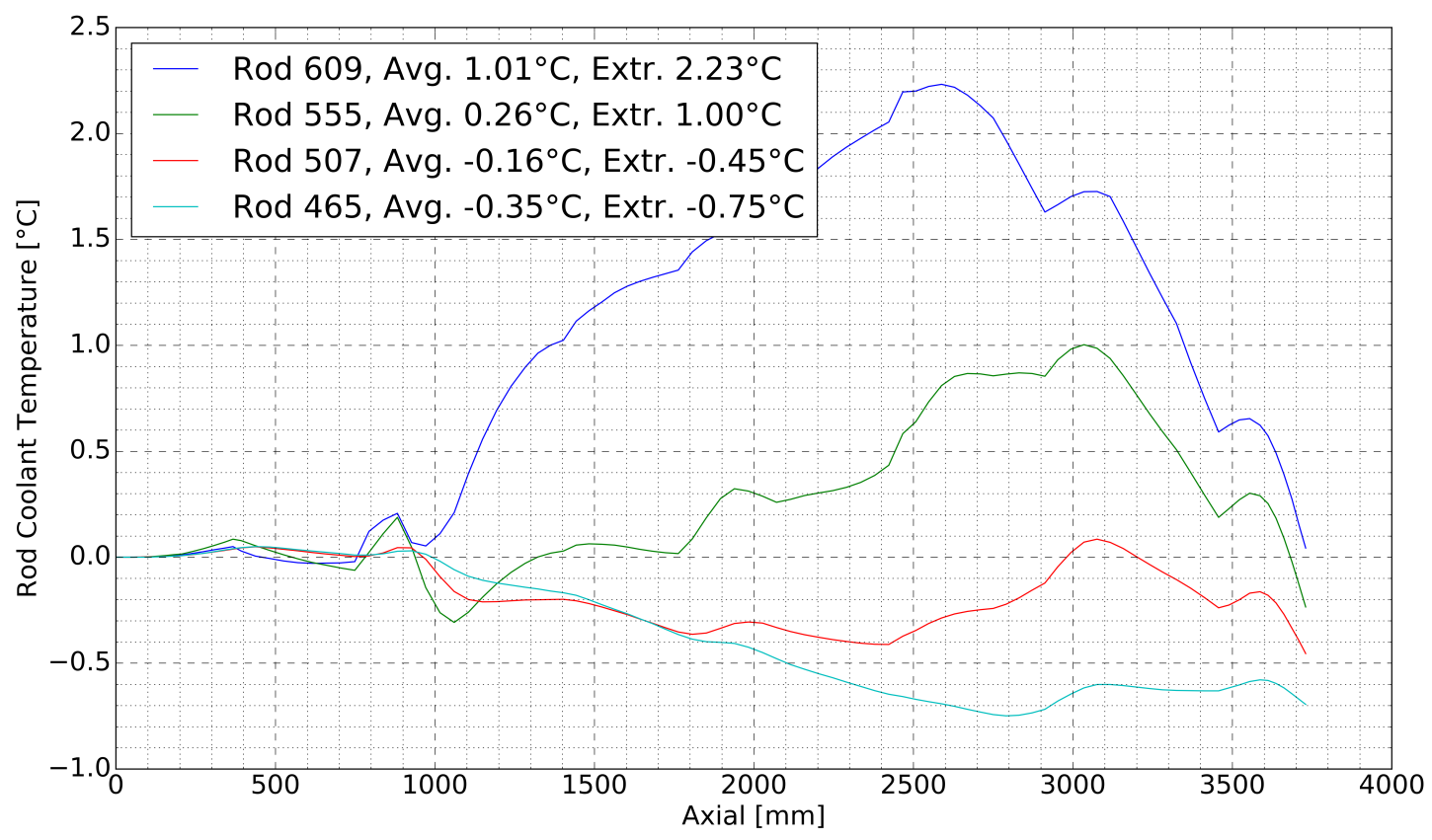

Figure 9. Example of rod coolant temperature differences - FA2. 


\section{Conclusions}

A subchannel model of three fuel assemblies was developed to evaluate mixed cores with the TVSA-T mod.1 and mod. 2 fuel assemblies. Two variants were created - the connection of three TVSA-T mod.1 fuel assemblies and the TVSA-T mod.2 fuel assembly with two TVSA-T mod.1. To evaluate the influence of mixed core on the coolant temperature and the crossflow, two mixed core fuel cycles were analyzed by code ANDREA. Six groups of fuel assemblies forming these mixed cores were selected from different positions in the core and these power profiles were used for further evaluation. By comparing all the results it was found that differences between these different power profiles are not significant at the crossflows nor at the coolant temperatures [5].

The crossflow coolant velocities were evaluated for both variants. Maximum values of the crossflow coolant velocities in the mixed core reached $1 \mathrm{~m} \mathrm{~s}^{-1}$ and the significant influence of the position of spacing grids and the value of their resistance was observed. The inaccuracies in the calculations were introduced by inputting the same value for each subchannel for mixing grids in TVSA-T mod.2 fuel assemblies, because the exact values of resistances specific to subchannel type was not known, while for mod.1 different resistances into subchannel types was used (more corresponding to reality).

A comparison of the crossflow velocity calculated by subchannel code SUBCAL and CFD code ANSYS CFX [2] was also performed. It should be noted that this comparison has several limiting factors. The CFD calculation, unlike the subchannel, was carried out only for the selected area of three spacing grids and with zero power on all fuel rods, i.e. without heating of the coolant. The quantities obtained by the subchannel analysis are on the other hand averaged over entire subchannel or boundary whose dimensions are several times larger than those used for CFD calculation. Taking these differences into account, the results of both methods are in good agreement.

Evaluation of coolant temperatures around fuel rods was performed in several rows at the boundary of two fuel assemblies. From all calculation, it can be seen that the influence of the mixed core on the coolant temperature around the fuel rods may reach a maximum of $5{ }^{\circ} \mathrm{C}$. It should be noted that the increase in coolant temperature also occurs in subchannels around guide tubes whose diameter has increased from $12.6 \mathrm{~mm}$ (mod.1).

The prepared three fuel assemblies model can also be used to evaluate the combination of two TVSAT mod.2 fuel assemblies and one TVSA-T mod.1 or mixed cores with other hydraulically non-identical fuel assemblies. Another possibility is, for example, the sensitivity analysis of DNBR in mixed cores.

\section{REFERENCES}

[1] J. Čížek, J. Krejčí. SUBCAL-ETE Dokumentace programu, 108084.9385\%. Chemcomex, 2010.

[2] TVEL. 03-TEM-TH-05.002 GIDRODINAMICHESKIY RASCHET PO CFD KODU DLYA USLOVIY SMESHANNOY AKTIVNOY ZONY, Rev.0, 2015.

[3] J. Čížek, V. Caha, J. Krejčí. 01-TH Metodika bezpečnostního hodnoceni palivových vsázek, Rev. 4 , 108368.171437. Chemcomex, 2017.

[4] J. Hejzlar. ANDREA Mixed core calculation: Cycles T1 and T2. ÚJV Řež, 2016.

[5] J. Čížek, V. Caha. Analýza vlivu př́čného proudění mezi PS na TH charakteristiky chladiva ve směsné zóně, Rev. 1, 00.417.112. Chemcomex, 2017.

[6] V. Caha, J. Č́ížek. SUBCAL-ETE Koeficient turbulentního míšení: TVSA-T mod.2, Rev. 0, 00.432.179. Chemcomex, 2016. 